\title{
Factoring as a Form of Financing Small and Medium-Sized Enterprises in ASEAN
}

\author{
Thi My Huong Do \\ Correspondence: Thi My Huong Do, Master of International Economics and Finance, The University of Queensland, \\ Australia; Lecturer at Banking Academy, 441 Nguyen Hue, Ward 7, Phu Yen, Vietnam.
}

Received: March 6, 2018

doi:10.11114/aef.v5i3.3175
Accepted: March 26, $2018 \quad$ Available online: April 4, 2018

URL: https://doi.org/10.11114/aef.v5i3.3175

\begin{abstract}
Small and medium-sized enterprises have increasingly played very important roles, particularly in developing open economies and the ASEAN economic community. One of the biggest factors that hinders the growth of these firms is their lack of fund and limited access to financial sources. This writing, firstly, aims to illustrate that factoring can prove to be a popular tendency in fanancing small and medium enterprises in ASEAN by showing its considerable growing rate over the last two decades. In the second part, using the OLS, the paper also measures and discusses the determinants of factoring development in three financial markets including Malaysia, Thailand, Singapore.
\end{abstract}

Keywords: factoring, financing, small and medium enterprises (SMEs), ASEAN

\section{Introduction}

\subsection{Introducing the Problem}

Accounting for $98.4 \%$ of all kinds of firms and $72 \%$ of labor force in ASEAN, SMEs are considered as the backbone of this regional economy with their considerable contribution to GDP. In 2012, SMEs made up 85\% of total GDP in Cambodia, $46.3 \%$ in Singapore, 56.5\% in Indonesia, 36.7\% in Thailand, 35.7\% in Philippines, $31.9 \%$ in Malaysia, 26\% in Vietnam, 22\% in Brunei (ADB, 2012). In spite of their essential economic role, SMEs have been facing numerous difficulties to overcome in an open and serve competition environment.

One of the greatest problems is their limited access to affordable financial sources (ADB, 2013). In 2012, all loans for SMEs accounted for $25 \%$ of all bank loans on average. In addition, SMEs also made up a large proportion of bad debts in developing countries in Asia (ADB, 2013). Therefore, it can be seen that there is a big gap between supply and demand for SMEs funding, as well as deficidency in tradition lending methods. Effective alternatives need to be addressed to solve this problem. Among them, compared to others, factoring is becoming one of the most possible solutions to overcome the limitations in small and medium enterprise funding in ASEAN. Thus, the purpose of this paper is to illustrate this tendency and its advandtages over other alternatives. Moreover, another is to examine which are the main factors influencing the development of factoring in 3 major members including Malaysia, Thailand, Singapore, then, to give some policy implications.

\subsection{Theoretical Framework and Literature Review}

\subsubsection{Theoretical Framework}

Factoring is a process where the lender (factor) underwrites the extension of credits by purchasing accounts receivables of a given company. According to Unidroit Convention on International Factoring (1988), "the factor is to perform at least two of the following functions: finance for the supplier (seller of account receivables) including loans and advance payments; maintenance of accounts relating to the receivables; collection of receivables; protection against default in payment by debtors. Accordingly, a notice of the assignment of the receivables is to be given to debtors".

Three types of parties are involved in a factoring contract: the seller, the purchaser, and the factor. The factoring company provides working capital in cash for the seller against getting account receivables.

\subsubsection{Literature Review}

In order to eliminate and avoid the risk of asymmetric information between lenders and borrowers, banks usually set up strict requirements relating financial statements, credit rating, collateral security,... In the case of SMEs who are highly 
risky, Berger and Udell (1990) stated that it is beyond SMEs' capacity to meet those requirements. So, banks are usually afraid to lend SMEs and often set higher interest rates and fees to make up for their risks. Also, bad debt rate for SMEs seem higher than those of large firms (Beck, Demirguc-Kunt and Peria, 2008). Whereas, for factoring, loan decision and credit limit do not depend on borrowers'credit, but on the risks of account recievables themselves. This is because the property of account receivables are transfered from borrowers to lenders in factoring services. This is quite different from other traditional forms, in which account receivables are termed simply as collaterals to lenders (Klapper,2006b). If borrowers go bankcrupt, the amount of account recievables will not be accounted as assets for insolvency, consequently, the right of creditors to receivables are guaranteed. Based on this advantage, factoring can be considered as a way to unblock the bottleneck of the asymmetric information problem. Even if SMEs are unable to meet bank requirements on lending, they can access credit via using factoring, particularly when SMEs are sellers in supply chain with big purchasers or prestidge foreign buyers from developed countries (Bakker, Klapper, Udell,2004). This is a common case for international trade when exporters in developing countries are selling out to importers in developed countries (Klapper,2006a). It is the buyers, who are large and credit-worthy foreign purchasers, not the sellers (SMEs) will pay for debts to creditors. In this case, it is unneccesary for factors to be concerned about the creditability of lenders or SMEs, which cannot be implemented for traditional tools of financing. Hence, factoring should be accepted and widely used for economies containing a great number of high-risk SMEs (Pham Truong Loc \& Vu Thi Dan Tra, 2013a).

\subsection{Research Design}

What are the determinants of importance of factoring in an economy?

Credit information system plays an important role in determining the availability of credit, lending product lists, as well as the importance of factoring in that list. One key function of credit information system is to collect and record the borrowers'credit history including their credit-worthiness, which can solve the problem of asymmetric information between debtors and creditors. Credit information centers will record the past obligations of firms and also predict their credit-worthiness in the future. Based on this, it is possible to assess the risk rate of receivables in factoring. In a recent study in 40 countries, Klapper (2006) showed that the ability to access credit information history was considered as a significant contributor to reduce credit risk in factoring, as well as to implement factoring agreements. Also, Klapper (2006) illustrated that reverse-factoring in Mexico could be seen as a successful model, in which factoring was rapidly developed based on a good credit information center using electronic channels and platforms.

Miller (2003) focused on the importance of credit information infrastructure. It is stated that if there isn't any credit information centers, the time needed to process loans and the cost of lending, and the rate of insolvency will be higher. It is also analysed in the study of Jappelli and Pagano (2010) that the more credit information is being shared in the community, the more access to capital firms can get. Credit information systems may include public and private centers (Bakker, Klapper and Udell, 2004).

Legal framework. According to Klapper (2006), factoring can still develop well in some countries even if their trade laws and their enforcement or implementation prove to be uneffective. This means that factoring can grow in a financial system with inefficient legal framework. Klapper provided empirical evidences in 48 countries that legislation on creditors' rights made less significance in the development of factoring. This can be explained by the transfer of receivables'ownership from debtors to creditors (factoring institutions) when receivables are sold to factoring institutions (creditors). In the event that the rights of creditors are not clearly stated and tightly controlled by the law, receivables will not be calculated as insolvent assets and will not be liquidated to pay off outstanding debts. Instead, these receivables will set to become the assets of factoring companies. Pham Truong Loc và Vu Thi Dan Tra (2013) also proved that reverse factoring model can become a successful financing method even in the economies with uneffective business environment or inefficient legal framework like Mexico, Phillipines, Bangladesh.

Although legal environment is not a key direct determinant of factoring development, it still affects factoring development conditions to some extent, particularly ones related to cost, as well as the effectiveness of debt collection. Thus, if there is a lack of efficient legal environment, debt collection will be more costly and less effective. As a result, the advantages of factoring will be reduced and the significance of factoring will be eliminated, hence the number of factoring customers may decrease ultimately. Moreover, inefficient legal framework will reduce the recoursement right of factoring companies in case of recourse factoring.

Factoring environment. Bakker, Klapper and Udell (2004) also state that tax structure and factoring environment make great influence on factoring turnover. Many types of taxes applied will hinder the pace of development of factoring industry. Additionally, serve regulations on exchange rate will harm its growth rate.

In order to measure three above factors, the following indexes are applied. Credit information will be accessed by Public Credit Registry Coverage/adult (\%) and Private Credit Registry Coverage/adult (\%). Legal framework will be accessed by Creditor rights index. Factoring environment will be accessed by the time and cost of contract enforcement 
(Bakker, Klapper and Udell, 2004).

\section{Method}

Data: The writing mainly uses secondary data collected from annual reports of FCI (Factors Chain International) and WB (World Bank) from 1994 to 2014.

Methodology: The paper applies OLS with one dependent variables including factoring turnover/GDP (\%) and two independent variables including export value/GDP (\%), private credit/GDP (\%), which aims to estimate the determinants of factoring development in a quantitative result. The model is illustrated as followed:

$$
\text { Factoring / GDP }=\beta_{1}+\beta_{2} \text {.Credit / GDP }+\beta_{3} \text {. Export / GDP }+e
$$

Factoring/GDP presents for factoring turnover to GDP $(\%)$, which means the contribution and importance of factoring in an economy. The higher this rate is, the more important factoring is. Credit/GDP stands for credit to private sector to GDP \%. This rate shows the growth rate of financial markets. The higher this rate is, the more developed the financial market is. Export/GDP illustrates the export value to GDP (\%).

\section{Results and Discussion}

\subsection{Factoring Figures in ASEAN Countries}

As seen from this chart, the importance of factoring and its contribution to GDP differs dramatically in various member countries. In Singapore, factoring/GDP is higher than the world's average rate and the highest rate in the region from 1994 until 2015. Singapore is followed by Thailand and Malaysia. Although the rate is lower than the world's average rate, its contribution to GDP takes over 1\% of GDP, which makes a certain significance of factoring to the economy. For others including Indonesia, Vietnam, Philippines, factoring has alson been applied for a long time, but its importance is still limited. Also, there is almost no turnover for Brunei, Myanmar, Laos, Cambodia.

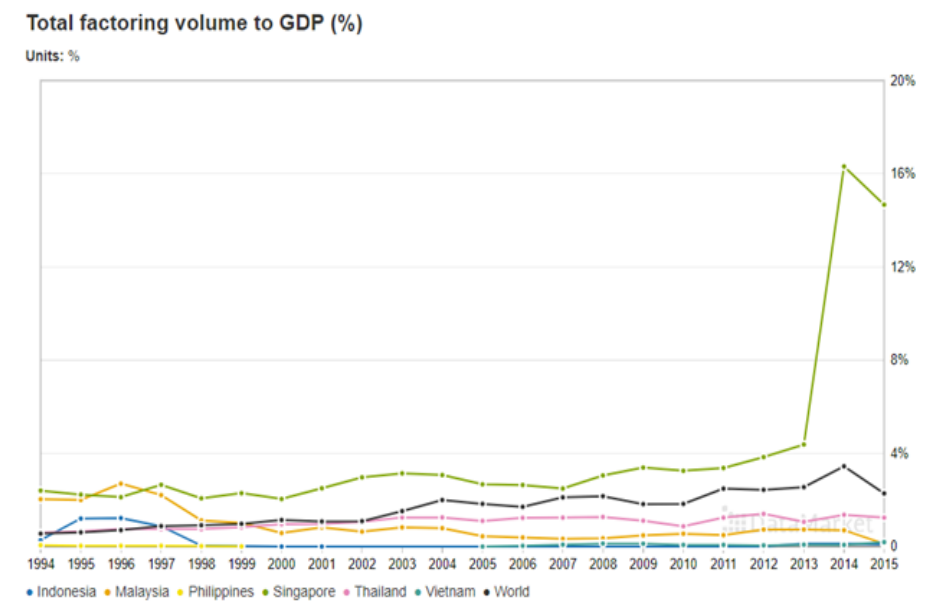

Figure 1. Factoring/GDP in 6 ASEAN countries from 1994 to 2015

Source: World Bank (citing: Factors Chain International)

According to Table 2, between 2010 and 2014, while global factoring turnover has risen at $42.42 \%$, this number in Asia is much higher, accounted for $73 \%$. The most impressive case is for Singapore and Thailand with the highest growth rate among others. Malaysia has a fairly rapid growth rate but still slower than Asian average number. For Indonesia, factoring has been developed again since 2011. In Vietnam, factoring has recently developed at a slow pace compared to other ASEAN members. In summary, the regional growth rate is higher than the world's average rate, but inconsistent within different members in the region. Thus, it can be drawn that ASEAN is very potential to develop in the next coming years (FCI, 2015).

Table 2. Factoring growth rate in ASEAN from 2010-2014 (Unit: EUR millions)

\begin{tabular}{c|c|c|c|c|c|c}
\hline Year/Country & 2010 & 2011 & 2012 & 2013 & 2014 & Growth rate (\%) \\
\hline Indonesia & - & 3 & 3 & 819 & 810 & - \\
\hline Malaysia & 1058 & 1050 & 1782 & 1782 & 1782 & 68.43100189 \\
\hline Singapore & 5800 & 6670 & 8670 & 9970 & 37840 & 552.4137931 \\
\hline Thailand & 2095 & 3080 & 4339 & 3348 & 4144 & 97.80429594 \\
\hline Viet Nam & 65 & 67 & 61 & 100 & 100 & 53.84615385 \\
\hline Asia & 355463 & 507694 & 571528 & 599297 & 614994 & 73.01209971 \\
\hline Thế giới & 1648330 & 2014978 & 2132186 & 2208372 & 2347513 & 42.41765909 \\
\hline
\end{tabular}

Source: Calculated from FCI Annual Report 2015 
In spite of impressive growth rate, the regional factoring turnover is quite limited and moderate compared to other Asian countries, except the case of Singapore, Thailand and Malaysia. As can be seen from Figure 2 and Figure 3, the regional number has made only $7 \%$ of the total of Asia, in which Singapore accounted for 85\%, Thailand 9\%, Malaysia 4\%, Indonesia $2 \%$ và Viet Nam just only $0.0224 \%$ of the total.

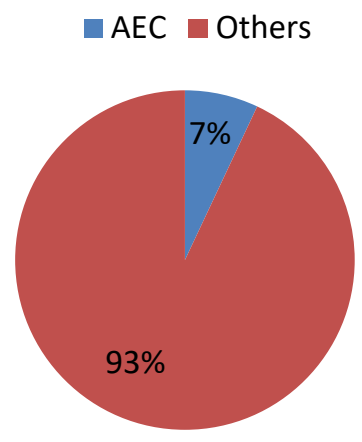

Figure 2. Percentage of factoring turnover compared to Asia in 2014.

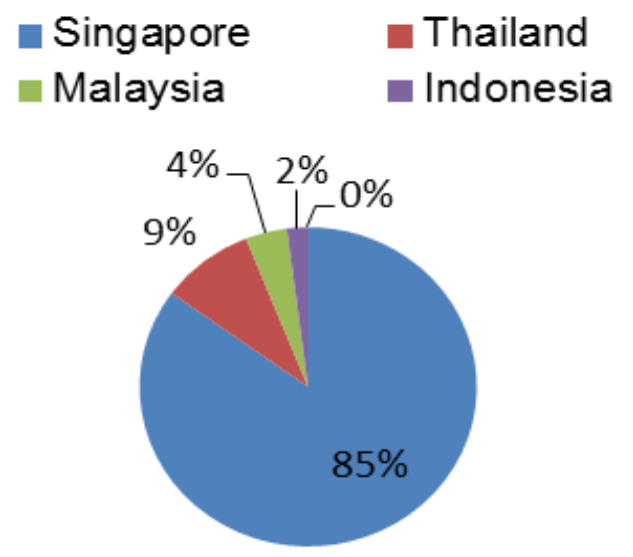

Figure 3. Percentage of factoring turnover in ASEAN in 2014.

\subsection{Determinants of Factoring Development in ASEAN Countries}

The estimated model OLS is applied to estimate the determining factors on factoring growth in three selected countries including Singapore, Thailand, Malaysia. The result is shown as followed.

Table 3. Result of OLS model

MALAYSIA

\begin{tabular}{|c|c|c|c|c|}
\hline Variable & Coefficient & Std. Error & t-Statistic & Prob. \\
\hline $\mathrm{C}$ & -0.068408 & 0.059970 & -1.140709 & 0.2698 \\
\hline D(LOG_EXPORT/GDP) & -2.564946 & 0.898418 & -2.854959 & 0.0110 \\
\hline D(LOG_CREDIT/GDP) & 1.782196 & 0.841261 & 2.118481 & 0.0492 \\
\hline \multicolumn{5}{|l|}{ THAILAND } \\
\hline Variable & Coefficient & Std. Error & t-Statistic & Prob. \\
\hline $\mathrm{C}$ & -0.889285 & 0.436041 & -2.039451 & 0.0564 \\
\hline EXPORT/GDP & 0.023003 & 0.004038 & 5.696629 & 0.0000 \\
\hline CREDIT/GDP & 0.003927 & 0.002175 & 1.805341 & 0.0878 \\
\hline \multicolumn{5}{|l|}{ SINGAPORE } \\
\hline Variable & Coefficient & Std. Error & t-Statistic & Prob. \\
\hline $\mathrm{C}$ & 12.61622 & 5.311773 & 2.375143 & 0.0289 \\
\hline LOG_EXPORT/GDP & -2.676731 & 1.084874 & -2.467320 & 0.0239 \\
\hline LOG_CREDIT/GDP & 0.679879 & 0.162507 & 4.183700 & 0.0006 \\
\hline
\end{tabular}


The resulting table shows that the development of financial market (presented by the variable Credit/GDP) has positive impact on factoring in all three countries (t-statistics $>1,64$ and $\mathrm{p}$-value $<10 \%$ ). This result is the same as the study conducted by Bakker, Klapper, and Udell (2004) in 8 European countries. In order to have a more detail analysis, the paper may also apply some indexes that have much influence on the development of financial markets, as well as legal and factoring environment including Strength of legal rights index, Public credit registry coverage, Private credit bureau coverage, Time, Cost.

Table 4. Index on the determinants of factoring in ASEAN in 2014

\begin{tabular}{l|c|c|c|c|c}
\hline & $\begin{array}{c}\text { Strength of legal rights } \\
\text { index (0-12) }\end{array}$ & $\begin{array}{c}\text { Public credit registry } \\
\text { coverage }(\% \text { of adults) }\end{array}$ & $\begin{array}{c}\text { Private credit } \\
\text { bureau coverage } \\
(\% \text { of adults) }\end{array}$ & $\begin{array}{c}\text { Time } \\
\text { (days) }\end{array}$ & $\begin{array}{c}\text { Cost }(\% \text { of } \\
\text { claim) }\end{array}$ \\
\hline Viet Nam & 7 & 39.1 & 0 & 400 & 29 \\
\hline Singapore & 8 & 0 & 53 & 150 & 25.8 \\
\hline Malaysia & 7 & 52.9 & 77.2 & 425 & 37.3 \\
\hline Thailand & 3 & 0 & 49.2 & 440 & 15 \\
\hline Indonesia & 4 & 41.2 & 0 & 471 & 115.7 \\
\hline
\end{tabular}

Source: World Bank Group (2015).

As can be observed in previous years and seen in 2014, the development of factoring in three countries like Singapore, Malaysia, Thailand is mostly contributed by a well-developed financial market covered with a wide private credit bureau system and a good legal system with strong rights for creditors, as well as attractive factoring environment. In Vietnam, despite a good legal system, the nation may lack of efficient credit information units, which may result in insufficient factoring industry in this country. For Thailand, thank to a wide coverage of private credit bureau and a good factoring environment, factoring has experienced a dramatic increase over the last period. For the case of Malaysia, even though this country has a very good legal system and wide coverage of public and private credit bureau, factoring industry is quite restricted due to inefficient factoring environment with high cost of claim (37.3\%). The last one, Singapore, is the most outstanding within the region based on its most effective credit information sysem, factoring environment as well as strict legislations.

From the above ananlysis, it can be seen that the most important factor affecting the development of factoring in AEC is the existence of a complete credit bureau system with effective credit units. Thailand can be taken as a good example. Even though Thailand's legislation on creditors' rights is ranked the lowest, it is owing to a widespread and effective private credit information system that is a great contributor to the development of factoring in this country. However, it should be kept in mind that this is not the only determining factor, but factoring environment and legal system on creditors' rights. For Malaysia, despite its more highly-ranked public and private credit coverage index, its factoring environment is said to be uneffective due to higher cost and more complicated procedure. Hence, Malaysia factoring turnover is illustrated lower than Singapore, who is the most developed financial market.

\section{Conclusion}

In conclusion, the existence of an efficient credit information system with a wide coverage of private credit units is a key factor and the most important determinant of factoring development in ASEAN countries. Secondly, although this is the most determining factor, it is not the only factor determining the growth of factoring in a certain economy. Others may include an efficient factoring environment and a complete legal right legislation system. Based on this analysis, policy makers in the region should take these ideas into consideration when promoting feasible methods to develop factoring as a financing for small and medium enterprises.

\section{References}

ADB. (2012). A new regime of SME Finance in Emerging Asia: Empowering Growth-Oriented SMEs to build resilient national economies. $A D B$ working paper series on regional economic integration. No 104.2.

ADB. (2013). Asia SME finance monitor. p.5-6. ADB Publiscation. Phillippines. ISBN 978-92-9254-491-1.http://www.adb.org/publications/asia-sme-finance-monitor-2013

Bakker, M., Klapper, L., \& Udell, G. (2004). Financing Small and Medium-size Enterprises with Factoring: Global growth in Factoring-and its Potential in Eastern Europe, Policy research working papers.7-11.

Beck, T., Demirguc, K. A., \& Peria, M. (2008). Bank financing for SMEs around the World.: Drivers, Obstacles, Business Models, and Lending Practices. Policy research working paper 4785.1-16.

Berger, A. N., \& Gregory, F. U. (1990). Collateral, Loan Quality, and Bank Risk. Journal of Monetary Economics, 25, 21-42. https://doi.org/10.1016/0304-3932(90)90042-3

FCI (Factoring Chain International). (2015). Annual Review 2015. 
Jappelli, T., \& Pagano. M. (2001). Information Sharing, Lending and Defaults: Cross-Country Evidence. Journal of Banking and Finance, 26, 2023-2054.

Klapper, L. (2006a). Export financing for SMEs: the role of factoring. World Bank Group, Trade Note, 29.

Klapper, L. (2006b). The role of factoring for financing small and medium enterprises. Journal of Banking \& Finance, 30(11), 3111-3130. https://doi.org/10.1016/j.jbankfin.2006.05.001

Miller, M. J. (2003). Credit Reporting Systems around the Globe: The State of the Art in Public Credit Reporting Firms and Private credit reporting firms.Credit Reporting Systems and the International Economy. Cambridge MIT Press.

Pham Truong Loc và Vu Thi Dan Tra. (2013a). Reverse factoring: An expected and potential factoring model in Vietnam. Vietnam Banking Review. Volumne 10.

WB. (2015). Data. http://data.worldbank.org/indicator/FS.AST.PRVT.GD.ZS

WB. (2015). Data. http://data.worldbank.org/indicator/NY.GDP.MKTP.CD

WB.(2015).https://datamarket.com/data/set/47dx/total-factoring-volume-to-gdp\#!ds=47dx!73c9=10.19.28.q.1n.13.b\&di splay=line

World bank Group. (2015). Doing business 2015: Indonesia Economy profile 2015. World bank report, $12^{\text {th }}$ edition. Washington.

World bank Group. (2015). Doing business 2015: Malaysia Economy profile 2015. World bank report, $12^{\text {th }}$ edition. Washington.

World bank Group. (2015). Doing business 2015: Singapore Economy profile 2015. World bank report, $12^{\text {th }}$ edition. Washington.

World bank Group. (2015). Doing business 2015: Thailand Economy profile 2015. World bank report, $12^{\text {th }}$ edition. Washington.

World bank Group. (2015). Doing business 2015: Vietnam Economy profile 2015. World bank report, $12^{\text {th }}$ edition.

\section{Copyrights}

Copyright for this article is retained by the author(s), with first publication rights granted to the journal.

This is an open-access article distributed under the terms and conditions of the Creative Commons Attribution license which permits unrestricted use, distribution, and reproduction in any medium, provided the original work is properly cited. 